\title{
Addressing the life cycle of sewers in contrasting cities through an eco- efficiency approach
}

Anna Petit-Boix, Carla Arnal, Desirée Marín, Alejandro Josa, Xavier Gabarrell, Joan Rieradevall

Address correspondence to: Anna Petit-Boix (anna.petit@uab.cat) - Sostenipra, Institute of Environmental Science and Technology, Universitat Autònoma de Barcelona (UAB), Edifici ICTA-ICP, Carrer de les Columnes, 08193 Bellaterra, Barcelona, Spain.

KEYWORDS: water cycle, life cycle assessment, life cycle costing, industrial ecology, eco-innovation

\section{SUMMARY}

Evaluating the sustainability of the urban water cycle is not straightforward, although a variety of methods have been proposed. Given the lack of integrated data about sewers, we applied the eco-efficiency approach to two case studies located in Spain with contrasting climate, population, and urban and sewer configurations. Our goal was to determine critical variables and life cycle stages and provide results for decision-making. We used life cycle assessment (LCA) and life cycle costing (LCC) to evaluate their environmental and economic impacts. Results showed that both cities have a similar profile albeit their contrasting features, i.e., operation and maintenance (O\&M) was the main environmental issue (50-70\% of the impacts) and pipe installation registered the greatest economic capital expenditure (70-75\%) due to labor. The location of the wastewater treatment plant (WWTPs) is an essential factor mainly due to the topography effects, e.g., pump energy was thirteen times greater in Calafell. Using the eco-efficiency portfolio, we observed that sewers might be less eco-efficient than WWTPs and that we need to envision their design in the context of an integrated WWTP-sewer management to improve sewer performance. In terms of methodological approach, the bi-dimensional nature of eco-efficiency enables the benchmarking of product systems and might be more easily interpreted by the general public. However, 
there are still some constraints that should be addressed to improve communication, such as the selection of indicators discussed in the paper.

\section{$<$ Heading Level $1>$ Introduction}

Meeting sustainability standards in cities is essential to ensuring the provision of urban services at low environmental, economic and social costs. One of these services is the urban water system, which calls for special attention given the increasing demand for water and sanitation that results from growing urban populations (UN 2012). However, evaluating the sustainability of this system is not straightforward. A variety of methods can be applied to assess the performance of the urban water cycle. For instance, multiple indicators have been used to cover some environmental, economic, socio-cultural, and/or functional criteria (Balkema et al. 2002; Venkatesh and Brattebø 2013; Hellström et al. 2000; van Leeuwen et al. 2012; Muga and Mihelcic 2008; Lemos et al. 2013; Fragkou et al. 2016). These were often combined through multi-criteria approaches to assess diverse sustainability objectives at different scales (Makropoulos et al. 2008; Marques et al. 2015).

Still, objective and comparable quantification is a challenge. We need to provide robust models and data to water facility managers so that they can apply the most viable options. In this respect, the eco-efficiency concept, normalized through ISO 14045:2012, can be particularly useful. This standard describes eco-efficiency assessment as "a quantitative management tool which enables the study of life-cycle environmental impacts of a product system along with its product system value for a stakeholder”. This tool lacks the social dimension of sustainability (Ehrenfeld 2005), but eco-efficiency is especially attractive because it might provide intrinsic information about potential social benefits (Ekins 2005). For instance, the product system value might be defined through consumer preferences. The need for a consistent approach 
(Brattebø 2005) is covered through ISO 14045:2012, which sets a methodological framework for assessing the eco-efficiency of products and systems.

In the field of urban water management, the eco-efficiency of sewer networks is worth analyzing. In general, there is an apparent interest in the absolute and relative environmental impacts of wastewater treatment plants (WWTP) around the world (Corominas et al. 2013), which have mainly been evaluated through life cycle assessment (LCA). However, few of these LCAs include the pipe infrastructure (Loubet et al. 2014). As opposed to WWTPs, which are generally affected by climatic conditions, a particularity of sewers is the effect of urban configuration on the energy required to operate the system (Petit-Boix et al. 2015). Within the existing literature, articles have mainly focused on the environmental impacts of the construction or full life cycle of sewers (Morera et al. 2016; Vahidi et al. 2015, 2016, Petit-Boix et al. 2016, 2014; Venkatesh et al. 2009; Risch et al. 2015) and a few studies have provided economic data (Akhtar et al. 2014; Thomas et al. 2016; Murla et al. 2016). Only Lorenzo-Toja et al. (2016) conducted an eco-efficiency benchmarking of WWTPs following ISO 14045:2012, but sewers were not analyzed.

In this context, what are the hotspots that might alter the eco-efficiency of sewers? Our goal was to apply the eco-efficiency approach to sewer networks in order to determine critical variables and life cycle stages and provide results and discussion for decision-making in the context of the urban water cycle. To address our questions, we based our assessment on two cities with contrasting urban conditions and climate in an attempt to represent major areas of the globe, i.e., an Atlantic city with year-round population and a Mediterranean, coastal city with seasonal population. To quantify the eco-efficiency of the systems, we followed the guidelines described in ISO 14045:2012. 
$<$ Heading level 2> Case study definition

To answer our research question, we studied two Spanish cities with different urban and climatic features in the framework of the LIFE+ Aquaenvec project (LIFE10/ENV/ES/520). These cities represent contrasting conditions that we used to test whether the eco-efficiency of sewers varies depending on the climate, population, and sewer and urban configurations. Betanzos is located in the northwest of Spain and has an Atlantic climate that results in more than 1,000 mm of rainfall every year. Wastewater flows from households to a WWTP located at sea level and most of the network is a gravity sewer due to the topography. In contrast, Calafell is a coastal, Mediterranean city with an annual rainfall of around $500 \mathrm{~mm}$. Because of land price and odor control, the WWTP was constructed inland and $40 \mathrm{~m}$ above sea level, which results in greater pumping requirements than in Betanzos (table 1). Both cities can be considered medium-sized based on their population (10,000 - 50,000 inhabitants), although in Calafell it usually doubles in the summer (Idescat 2016).

The sewer components were identified through the water managers and the SGO (Operation Management System) and CONTEC (Technical Control of the Integral Water Cycle) databases (@Suez services company 2012). These were mainly combined sewers, with a portion of stormwater network in Calafell. The network has a total length of 77 and $173 \mathrm{~km}$ in Betanzos and Calafell, respectively. They consisted of concrete, fibrocement, high-density polyethylene (HDPE) and polyvinylchloride (PVC) pipes. Both cities had a greater share of plastic pipes, i.e., 66\% of PVC in Betanzos and 73\% of HDPE in Calafell, and diameters of 300-315 mm dominated (50-75\% of the network). In the case of sewer appurtenances, the number of manholes and inspection chambers was estimated assuming one unit every 50 meters of sewer (Petit-Boix et al. 2014). The CONTEC database provided the number of scuppers, wastewater 
connections and submersible pumps (@Suez services company 2012). However, the power of the pumps was unknown and we tested a scenario with a $60 \mathrm{~m}^{3} / \mathrm{h}$ pump to account for the pump production, which is the highest flow we found in construction databases (MetaBase ITeC 2010). We did know the real electricity consumption of the system, and the wastewater production was registered at the WWTP.

$<$ Table $1>$

$<$ Heading level 2> Eco-efficiency assessment method

The methodological framework of an eco-efficiency assessment combines the environmental and value assessment of a product system (ISO 14045:2012). To do so, ISO 14045:2012 includes two specific requirements for choosing eco-efficiency indicators. The ratio between the environmental and value dimensions can either depict an improved environment at the same product system value or an improved product system value at the same environmental effect. These results can be represented through eco-efficiency portfolios that illustrate the pathway towards the desired eco-efficiency and can be used in the benchmarking of a product system using optimization functions. For a given functional unit (FU), practitioners should define the indicators applied, as these are not provided by the standard and might vary depending on the analysis.

In general, this ISO standard is relatively open and flexible in terms of methodological approaches. LCA is the method selected to conduct the environmental analysis based on ISO 14040:2006. In the case of the value assessment, the standard calls for an integration of the full life cycle of the product system, but does not establish a specific method for this type of analysis. Based on this ISO standard, the system value (i.e., its worth or desirability) can be functional, monetary or intangible (i.e., esthetic, cultural, etc.). Because of the life cycle perspective, we typically apply life cycle costing 
(LCC; ISO 15686-5:2008) and assess the monetary value of a product system. We used this method in our analysis to assess the costs associated with the sewer infrastructure.

\section{$<$ Heading level 2> Goal and scope definition}

In this study, we aim to assess the eco-efficiency of sewers by combining the environmental and economic dimensions through the LCA and LCC methods. The FU was the transport of one $\mathrm{m}^{3}$ of urban wastewater from the households to the WWTP in a medium-sized city through a sewer network. We considered different lifespans depending on the pipe material and sewer component. We assumed 100 years for concrete pipes (U.S. Army Corps of Engineers 1998; CPSA 2010) and 50 years for plastic pipes (UNE 53331:1997). A lifespan of 50 years was assigned to all types of appurtenances except for submersible pumps, which were replaced every 10 years (Petit-Boix et al. 2014).

To determine the environmental and economic results per FU, we followed the method proposed by Petit-Boix et al. (2014). Based on EN 15804:2011, we set different declared units for the construction assets, i.e., one linear meter of pipe-trench constructive solutions and one unit of each appurtenance. To account for the total impacts of the system, we scaled to the total sewer components (table 1) and combined with the operation and maintenance (O\&M) of the system.

The same system boundaries were considered in the LCA and LCC (figure 1). These included the raw material procurement, pipe production, transport to the construction site, pipe installation and trench preparation, and O\&M. The demolition was excluded because it was negligible (Petit-Boix et al. 2014; Gabarrell et al. 2013). The end-of-life stage was not accounted for because the pipe can be either disposed of or left underground. The LCA does not include the emissions that result from 
wastewater degradation on its way to the WWTP, such as methane, nitrous oxide, and hydrogen sulfide, because a model is still needed to predict the emissions of the entire network. According to Eijo-Río et al. (2015), these emissions might represent at least $4 \%$ of the O\&M impacts and should be accounted for in future assessments.

$<$ Figure $1>$

$<$ Heading level 2> Life cycle inventory (LCI)

Table 2 provides a detailed inventory of the material and energy flows involved in the life cycle of the sewers in Calafell and Betanzos. Note that the production and installation stage includes the pipes and appurtenances. The LCI of each sewer component is provided in Supporting Information 1. When inventorying the pipelines, we considered different trench designs depending on the pipe material. Based on the results reported by Petit-Boix et al. (2016), we adapted the worst designs to show the maximum environmental impacts of the system. Concrete pipe trenches had a bedding factor of 4, which is the highest safety level (EN 1916:2002) and consists of the largest amount of concrete bedding. Plastic pipes were embedded in sand imported from other areas. The excavated soil was left aside for other purposes and its management was outside of our scope. The appurtenance design was adapted from the literature (PetitBoix et al. 2014) and databases (MetaBase ITeC 2010; CYPE Ingenieros 2015).

Data on the energy consumed in the installation process and the materials used in the pipe production were retrieved from MetaBase ITeC (2010). A truck covered a distance of $100 \mathrm{~km}$ to transport plastics and metals to the construction site and $30 \mathrm{~km}$ to transport the remaining materials (Doka 2003). The ecoinvent v2.2 database (Frischknecht et al. 2005) was used to obtain background information on the life cycle of the materials and processes involved. 
The O\&M consisted of different variables. First, the energy required to pump wastewater to the WWTP was provided by the facility managers. The electricity was modeled using the Spanish mix of the year 2011 (REE 2012), which is the year that we obtained data from. Second, the length of sewer and number of appurtenances renovated every year was unknown. We assumed a certain number of repositions depending on their lifespan, e.g., when a component had a 50-year lifespan, we considered one reposition in 100 years. Only in the case of fibrocement did we assume a $2 \%$ renovation rate according to local estimates. Third, maintenance involved cleaning tasks, e.g., removal and transport of sediments accumulated in the sewers. This data was available in the case of Calafell and we considered the number of trips covered by the inspection and maintenance service (48 trips/year; $75 \mathrm{~km}$ ) and the average amount of sediments (4,000 kg/year). We could not apply these estimates to Betanzos, but assumed a negligible maintenance based on onsite observations

All the construction flows were translated into monetary values through MetaBase ITeC (2010) and CYPE Ingenieros (2015). The value assessment includes additional costs, such as labor, overheads, fees and indirect costs (figure 1). Labor and overhead data related to construction processes were available in the aforementioned databases. O\&M costs were retrieved from financial statements and invoices provided by utility managers. In this case, the reposition costs of 2011 were obtained, but the reposition rate was not available. Due to limited data availability, the economic costs were not broken down into basic flows. The total cost of each sewer component is provided in the Supporting Information 2.

$<$ Table 2>

$<$ Heading level 2> Life cycle impact assessment (LCIA) and indicator selection 
The selection of environmental indicators might be more complex when communicating eco-efficiency results. In the eco-efficiency portfolios only one indicator can be represented and selecting one or another might lead to the common tradeoffs that occur in LCA studies. For this reason, we conducted the impact assessment at three levels, i.e., using midpoints, endpoints, and a single score indicator. These were modeled with the ReCiPe (H) method (Goedkoop et al. 2009) and the Simapro 8 software (PRé Consultants 2014).

We used endpoints to determine the specific damage of the production, installation, and O\&M to human health, ecosystems and resources. As we were interested in determining hotspots in the eco-efficiency of sewers, endpoints might reduce the complexity of interpretations because decision-makers do not need to identify the environmental relevance of each midpoint indicator (Bare et al. 2000). This can also be achieved through an integrated single score indicator, which represents the weighted endpoints in terms of eco-points (Pt). Although endpoint and single score indicators have an increased uncertainty and subjectivity with respect to midpoints, we used them in the eco-efficiency assessment for an easier understanding and communication. Some argue that endpoints provide a more structured factor weighting when comparing (Udo de Haes et al. 2002), as they are closer to our concerns, such as health issues, and can be easily valuated (Hertwich and Hammitt 2001). Nevertheless, there is a loss of comprehensiveness and increased uncertainty in endpoint and damage analysis due to the modeling principles, assumptions and value choice (Bare et al. 2000).

For this reason, a recommendation is to provide both the midpoint and endpoint results to increase the transparency of the analysis (Kägi et al. 2016). We used a set of 18 ReCiPe midpoints and the Cumulative Energy Demand (CED) (Hischier et al. 2010) 
to break down the environmental impacts into sewer components and O\&M flows. By doing so, we identified the impacts generated by basic flows (e.g., materials, energy, etc.) at early stages of the cause-effect chain, such as the potential resource depletion or pollutant emissions.

\section{$<$ Heading level 2> Economic indicator selection}

The economic costs were calculated differently in the construction and O\&M processes. The O\&M costs were based on the financial statement of the water facilities, which include the energy, fees and indirect operation costs. In the case of the pipe production and installation, the direct unit costs (DUC) resulting from the LCI were converted into equivalent annual costs (EAC). By doing so, we accounted for the annual costs of the sewer construction considering a time horizon of 100 years, which is the potential maximum lifespan of concrete pipes. Equations (1), (2), and (3) illustrate the conversion of the DUC into EAC. To calculate the total unit cost (TUC), we considered that the indirect costs (IUC) were $10 \%$ of the DUC. The general costs (GUC) and industrial profit (IP) represented 13\% and 6\% of the execution material budget (i.e., direct plus indirect costs), respectively (BOE 2001). A 3\% interest rate was assumed to estimate the present value (PV) and EAC, with a time horizon of 100 years according to the FU of the analysis.

$$
\begin{aligned}
& T U C=D U C+I U C+G U C+I P=1.309 D U C \\
& P V=\frac{T U C}{(1+i)^{t}}(2) \\
& E A C=\frac{P V \times i}{1-(1+i)^{-n}}
\end{aligned}
$$


where TUC = total unit cost; DUC = direct unit cost; IUC = indirect unit cost; GUC = general unit cost; IP = industrial profit; PV = present value; EAC = equivalent annual costs; $\mathrm{i}=$ interest rate $(3 \%) ; \mathrm{t}=$ lifespan (present, $\mathrm{t}=0) ; \mathrm{n}=$ time horizon (100 years)

$<$ Heading level $1>$ Results and discussion

In this section, we identified the life cycle stages with a poor environmental and economic performance and sought possible explanations. These dimensions were compared and eco-efficiency results were discussed in the context of the urban water cycle.

$<$ Heading level 2> Environmental and economic characterization of the sewers

A set of environmental and economic results is shown in table 3 . The environmental and economic hotspots were similar in both cities, but the total impacts of Betanzos and Calafell were especially different. For instance, the impacts to human health were 4.1E-07 and 6.9E-07 DALYs m ${ }^{-3}$, respectively, whereas the total economic costs amounted to approximately $1 € \mathrm{~m}^{-3}$ in both cases.

$<$ Heading level 3> Identification of environmental hotspots

The O\&M was the most relevant phase of the environmental life cycle and contributed to approximately $50 \%$ and $70 \%$ of the impacts to human health, ecosystems and resources in Betanzos and Calafell, respectively. The main difference between both cities was the energy required to pump wastewater. Within the O\&M, the electricity accounted for $30 \%$ and $70 \%$ of the impacts in Betanzos and Calafell, respectively. These percent contributions to the endpoint indicators resulted from the midpoint breakdown shown in figure 2 (the acronyms and absolute midpoint results are shown in Supporting Information 3). The ionizing radiation (IR) is the category where electricity contributed most (around $90 \%$ ), as $21 \%$ of the Spanish energy demand was 
covered by nuclear power in 2011 (REE 2012). The contribution of the O\&M to the life cycle impacts might be even greater once the direct gas emissions are included in the assessment.

Besides the electricity consumption, the type of sewer component, material, design and lifespan had a relevant effect on the results. The sewer components can be classified in order from most to fewest impacts (figure 2). Depending on the impact category, plastic pipelines accounted for the largest impacts, with a maximum contribution of $40 \%$, followed by appurtenances (30\%) and concrete pipelines (10\%). The larger contribution of plastics can be easily associated with the length of sewer, as these were the main materials used in the pipeline. As shown in Supporting Information 3, the pipe itself had an irrelevant contribution to the total impacts $(<10 \%)$, but the trench played a key role in the construction stage as predicted by PetitBoix et al. (2014, 2016). In this case, we accounted for the worst case scenario, but Venkatesh et al. (2009) chose not to include the trench materials because they were reused from the excavation. The impacts of appurtenances were notable in the midpoints related to toxicity and metal depletion because iron and steel parts were used in their construction (table 2). Based on these results, the impacts of the O\&M increased due to the reposition needs. Plastic pipelines and appurtenances had shorter lifespans (50 years) than concrete pipes (100 years), which means that the reposition was related to the components with the greatest environmental impacts. An alternative might be to implement concrete pipelines that have a longer service life and better environmental performance.

\section{$<$ Heading level 3> Identification of economic hotspots}

Contrary to the environmental assessment, the installation stage resulted in the largest economic investment (table 3). The cost of this stage amounted to $0.72-0.73 € \mathrm{~m}^{-}$ 
${ }^{3}$, which represented $70 \%$ and $75 \%$ of the total investment made in Calafell and Betanzos, respectively. Because the O\&M included the fees, personnel, and recurring maintenance costs (named “others” in figure 2), we expected that these would account for a greater share of the annual expenses. However, they represented $10 \%$ of the total costs.

Labor was the reason why the installation was more expensive on an annual basis. The need for skilled construction workers resulted in $50 \%$ of the investment at this stage of the life cycle (see Supporting Information 2). In social terms, this investment might result in positive effects, as it enhances the staff recruitment in the area. It was also notable that plastic pipelines were the most expensive item in the system and accounted for $60 \%$ of the costs in both cities, which was also associated with the installation stage. As opposed to the LCA, note that we obtained real reposition costs and did not apply the equivalent costs of the initial construction of the sewer. In this case, the reposition was almost negligible.

$<$ Table 3>

$<$ Figure 2>

$<$ Heading level 3> Explanatory variables to local differences

The environmental and economic trends were very similar in both case studies. Nevertheless, the environmental effects of the O\&M stage were greater in Calafell (e.g., 5.1E-07 DALY m ${ }^{-3}$ ) than in Betanzos (e.g., 2.2E-07 DALY m³ ${ }^{-3}$. Previous analyses tried to explain general variations in the O\&M of sewers (Petit-Boix et al. 2015), but an analysis of specific case studies might help to delve deeper into the differences among cities. 
Different reasons might be associated with the energy requirements of these sewers, which are 0.11 and $0.47 \mathrm{kWh} \mathrm{m}^{-3}$ in Betanzos and Calafell, respectively. Some of them include the rainfall patterns, population, length of sewer, and location of the WWTP. We checked each of these variables to determine which one might be contributing most to the results of each city. Betanzos was expected to have an increased energy demand because the Atlantic climate results in constant rainfall throughout the year. Additionally, tides affect this region and might result in tidewater entries to the combined sewer (Day 2000). However, these effects were not apparent when comparing Betanzos to Calafell. The influence of population can be assessed through the wastewater generation per capita. Based on table 1, we estimated a wastewater production of 84 and $135 \mathrm{~m}^{3}$ capita $^{-1}$ year $^{-1}$ in Betanzos and Calafell, respectively. Nevertheless, Calafell had a seasonal inflow of 13,227 tourists that doubled the number of residents, so the total equivalent population should be applied instead (table 1) (Idescat 2016). The resulting wastewater generation was $87 \mathrm{~m}^{3}$ capita $^{-}$ ${ }^{1}$ year $^{-1}$, which is similar to that of Betanzos and does not explain the difference in energy consumption. The length of sewer needed to connect the city to the WWTP might influence the electricity consumption as predicted by Petit-Boix et al. (2015). Based on table 1, the length per $\mathrm{m}^{3}$ of wastewater was $0.05-0.07 \mathrm{~km}$, which does not explain the difference between the cities.

The last variable that we addressed was the location of the WWTP. Looking at urban planning, Calafell's WWTP was located at a higher altitude than that of Betanzos. Although Betanzos had intermediate pumping stations to deal with topographic variations, the WWTP was at sea level. Consequently, the energy intensity of the pumping system was thirteen times greater in Calafell. A set of pumping stations directed the wastewater flow to a larger station which was responsible for connecting 
the city to the WWTP through a rising sewer. The WWTP was three kilometers away from this point and $40 \mathrm{~m}$ above sea level. For this reason, we believe that the main variable that affected the O\&M was the location of the WWTP.

\section{$<$ Heading level 2> Assessing the eco-efficiency of sewers}

At this stage, we can apply the eco-efficiency portfolios to integrate the environmental and economic results and facilitate the decision-making process. Because the economic results (EAC) are based on an LCC, we showed the environmental effects associated with economic investment, which is the eco-efficiency type called environmental intensity of production (Huppes and Ishikawa 2005a).

In figure 3 we used a single score indicator to aggregate the environmental impacts in a single unit. With this approach, we could identify the pathway towards ecoefficiency in each life cycle stage. The shaded areas highlight the location of each life cycle stage in the portfolio based on the case-study results. When compared to the other life cycle stages, every euro invested in the O\&M resulted in large environmental impacts. Again, the highest values (e.g., $140 \mathrm{mPt} / €$ ) were associated with an increased energy consumption in Calafell, which had a low economic cost (figure 2). The opposite situation occurred in the installation stage. Here, the economic investment was high but mainly related to labor costs, which do not have an environmental equivalent. However, these might be an indirect measure of the number of workers involved, which could be a positive social indicator. We found similar results when we used the GWP instead of the single score indicator in the eco-efficiency representation (see the Supporting Information 4).

The portfolio also provides some guidance on the pathway towards eco-efficiency improvements. Given our findings on the effects of topography, a preliminary urban 
analysis is needed to find feasible locations of the WWTP that reduce the environmental footprint of the system. In contrast, the main concern in terms of infrastructure was the initial economic investment. When compared to the pipe and appurtenance production, the installation resulted in twelve times more costs. In this case, the type of trench design, which is concrete intensive, might require more labor hours than other solutions, suggesting that an optimization of the system is needed.

It is also interesting to put the sewers into the context of the water cycle. As a first estimation, we compared the eco-efficiency of our case study sewers with the average eco-efficiency of Spanish WWTPs based on Lorenzo-Toja et al. (2016). Through this comparison, we observed that the economic and environmental costs of Calafell's sewer were seven and two times greater than the WWTP average. When comparing it to Betanzos, the environmental impacts did not differ, but the economic costs were also seven times greater in the sewer. This is related to the construction phase, as the environmental impacts of constructing WWTPs are negligible when compared to the O\&M (Lorenzo-Toja et al. 2016; Termes-Rifé et al. 2013) because of the lifetime of the infrastructure. This showed that sewers are not irrelevant in the framework of the urban water cycle, meaning that decisions made at the design phase will determine their performance.

However, this can be challenging. The complexity of WWTPs is associated with the efficiency of the O\&M to meet water quality standards. In the case of sewers, indirect decisions might result in greater effects than the mere selection of pipe materials. Urban planning could have two main consequences on the eco-efficiency of sewers. A distant WWTP results in a longer pipeline; if it is located at a higher altitude than the city, this also involves more pumping energy. These decisions translate into avoidable economic investments in infrastructure and environmental burdens related to 
pumping energy. Therefore, there is a need to envision sewers in the context of the water cycle in order to design the system more eco-efficiently.

Still, sewer studies are underrepresented as compared to those dealing with the impacts and costs of water and wastewater treatment. Loubet et al. (2014) found that the environmental footprint of sewers is minimal in most studies, and the O\&M contributed to less than $10 \%$ of the total economic costs in a water cycle analysis elaborated by Venkatesh and Brattebø (2011). Most of these analyses do not account for trench materials or appurtenances and for this reason our results might be higher. In general, more efforts are needed to characterize sewers under different conditions to better understand their role in the water cycle.

$<$ Figure 3>

$<$ Heading level 2> On the application of eco-efficiency

Similarly to life cycle analyses, eco-efficiency is a robust communication tool, but we believe that it has a greater outreach potential. The bi-dimensional nature of this approach enables the benchmarking of product systems and it can be easily interpreted by the general public. Some problems arise, though, when deciding the environmental and economic indicators that define the product system. In our case, we used a measure of the environmental intensity of production. This means that the optimum ecoefficiency accounts for reduced environmental impacts generated through reduced production costs. On the one hand, monetary costs and LCC are commonly used when addressing the economic dimension, but one might argue that this approach is not complete because it does not cover aspects such as economic growth or value creation (Haes et al. 2004). On the other hand, we selected a set of indicators, but standards 
should provide some guidance and discuss the suitability of aggregated indicators in the context of eco-efficiency communication tools.

We proved that the procedure presented in ISO 14045:2012 can be applied to urban systems and provided integrated data for the decision-making process. An optimized system might serve as a reference for sewer benchmarking, but we did not provide this result because several parameters are at play. For instance, policies and social perceptions should be accounted for, as these determine the location and configuration of the sewer. Our approach serves as a first step towards integrating economic and environmental variables in the context of urban sanitation, which is helpful to decision-makers and might in fact change the social aspects associated with the impacts of sewers. Urban systems are a good example of micro-scale effects to macro-scale eco-efficiency, which is an approach to consider in order to avoid tradeoffs (Huppes and Ishikawa 2005b). If service providers (e.g., pipe manufacturers) improve their eco-efficiency, these might become more competitive in the market and result in further positive effects in the context of the urban water cycle and the overall performance of our cities.

$<$ Heading level $1>$ Conclusions

The eco-efficiency approach helped us to determine key hotspots in the environmental and economic performance of sewers. We studied two case studies with contrasting features in terms of population, climate, urban and sewer configuration, and yet we obtained similar trends. The critical life cycle stages were the O\&M in environmental terms, and the installation in economic terms. The impacts of the O\&M were associated with the location of the WWTP and the consequent energy needs. Labor was the main economic flow that affected the investment in the installation of sewers. This factor should be further assessed, as it might entail social benefits that are not 
directly captured by the eco-efficiency approach. Additionally, one of the sewers resulted in seven and two times as many economic and environmental impacts than an average WWTP. This means that sewers are in a critical and challenging position that calls for an integrated assessment of the urban water cycle.

To the authors' knowledge, this is the first application of ISO 14045:2012 to sewers. We believe that this is a method with a great potential in terms of communication, although integrating further social aspects should be considered. This study suggests that this type of assessment may well encourage water managers and local administrations to implement more sustainable alternatives in facility planning and management. Benchmarking their performance might be a compelling approach, as it shows their improvements with respect to similar services and drives their pathway towards a more eco-efficient behavior.

$<$ Heading level 1> Acknowledgements

We performed this study thanks to the LIFE+ Aquaenvec project (LIFE10/ENV/ES/520) “Assessment and improvement of the urban water cycle ecoefficiency using LCA and LCC”. The authors are grateful for the support of the Spanish Ministry of Education for the grant awarded to A. Petit-Boix (FPU13/01273) and Generalitat de Catalunya for funding the 2014 SGR 1412.

$<$ Heading level $1>$ References

(C) Suez services company. 2012. CONTEC (Control Técnico del Ciclo Integral del Agua) and SGO (Sistema de Gestión Operativa). (CAqualogy services company.

Akhtar, S., B. Reza, K. Hewage, A. Shahriar, A. Zargar, and R. Sadiq. 2014. Life cycle sustainability assessment (LCSA) for selection of sewer pipe materials. Clean Technologies and Environmental Policy 17(4): 973-992. 
http://link.springer.com/10.1007/s10098-014-0849-x. Accessed March 13, 2015.

Balkema, A.J., H.A. Preisig, R. Otterpohl, and F.J.. Lambert. 2002. Indicators for the sustainability assessment of wastewater treatment systems. Urban Water 4(2): $153-161$.

Bare, J.C., P. Hofstetter, D.W. Pennington, and H.A.U. de Haes. 2000. Midpoints versus endpoints: The sacrifices and benefits. The International Journal of Life Cycle Assessment 5(6): 319-326. http://link.springer.com/10.1007/BF02978665. Accessed August 18, 2016.

BOE. 2001. Real Decreto 1098/2001 de 12 de octubre, por el que se aprueba el Reglamento general de la Ley de Contratos de las Administraciones Públicas 257.

Brattebø, H. 2005. Toward a Methods Framework for Eco-efficiency Analysis? Journal of Industrial Ecology 9(4): 9-11. http://doi.wiley.com/10.1162/108819805775247837.

Corominas, L., J. Foley, J.S. Guest, A. Hospido, H.F. Larsen, S. Morera, and A. Shaw. 2013. Life cycle assessment applied to wastewater treatment: state of the art. Water Research 47(15): 5480-92. http://www.sciencedirect.com/science/article/pii/S004313541300540X. Accessed October 1, 2014.

CPSA. Concrete Pipeline Systems Association. 2010. PAS 2050- partial lifecycle assessment. Cradle-to-gate analysis for concrete pipeline. Manhole Ring and Cover Slab. Leicester.

CYPE Ingenieros. 2015. Construction costs generator [Generador de precios de la construcción] http://www.generadordeprecios.info/. 
Day, T.J. 2000. Sewer management systems. John Wiley \& Sons.

Doka, G. 2003. Ecoinvent report No. 13, Part IV: Wastewater Treatment. Ecoinvent report for v1.3.

Ehrenfeld, J.R. 2005. Eco-efficiency Philosophy, Theory, and Tools. Journal of Industrial Ecology 9(4): 6-8.

Eijo-Río, E., A. Petit-Boix, G. Villalba, M.E. Suárez-Ojeda, D. Marin, M.J. Amores, X. Aldea, J. Rieradevall, and X. Gabarrell. 2015. Municipal sewer networks as sources of nitrous oxide, methane and hydrogen sulphide emissions: A review and case studies. Journal of Environmental Chemical Engineering 3(3): 2084-2094. http://www.sciencedirect.com/science/article/pii/S2213343715001773. Accessed August 24, 2015.

Ekins, P. 2005. Eco-efficiency: Motives, Drivers, and Economic Implications. Journal of Industrial Ecology 9(4): 12-15.

EN 15804:2011. Sustainability of construction works - Environmental product declarations - Core rules for the product category of construction works. European Standard. Brussels, Belgium: European Committee for Standardization.

EN 1916:2002. Concrete pipes and fitting, unreinforced, steel fibre and reinforced. AENOR, Madrid, Spain.

Fragkou, M.C., T. Vicent, and X. Gabarrell. 2016. An ecosystemic approach for assessing the urban water self-sufficiency potential: lessons from the Mediterranean. Urban Water Journal 13(7): 663-675.

Frischknecht, R., N. Jungbluth, H.-J. Althaus, G. Doka, R. Dones, T. Heck, S. Hellweg, et al. 2005. The ecoinvent database: Overview and methodological framework. 
International Journal of Life Cycle Assessment 10: 3-9.

Gabarrell, X., J. Rieradevall, and C. Gasol. 2013. LCADB.sudoe. Base de datos para la realización de Análisis del Ciclo de Vida para la región Sudoe. Register of Community Trade Marks No: 010999373.

Goedkoop, M., R. Heijungs, and R. Huijbregts M, De Schryver A, Struijs J, Van Zelm. 2009. ReCiPe 2008, A Life Cycle Impact Assessment Method Which Comprises Harmonised Category Indicators at the Midpoint and the Endpoint Level. Report I: Characterisation. First Ed. Available at: http://www.lcia-recipe.net.

Haes, H.A.U., R. Heijungs, S. Suh, and G. Huppes. 2004. Three Strategies to Overcome the Limitations of Life-Cycle Assessment. Journal of Industrial Ecology 8(3): 1932. http://doi.wiley.com/10.1162/1088198042442351. Accessed September 1, 2016.

Hellström, D., U. Jeppsson, and E. Kärrman. 2000. A framework for systems analysis of sustainable urban water management. Environmental Impact Assessment Review 20(3): 311-321.

Hertwich, E.G. and J.K. Hammitt. 2001. A decision-analytic framework for impact assessment. The International Journal of Life Cycle Assessment 6(5): 265-272. http://link.springer.com/10.1007/BF02978787. Accessed February 13, 2017.

Hischier, R., B. Weidema, H. Althaus, C. Bauer, G. Doka, R. Dones, R. Frischknecht, et al. 2010. Implementation of Life Cycle Impact Assessment Methods. Final report ecoinvent v2.2 No. 3 .

Huppes, G. and M. Ishikawa. 2005a. Eco-efficiency and Its Terminology. Journal of Industrial Ecology 9(4): 43-46. 
Huppes, G. and M. Ishikawa. 2005b. A framework for quantified eco-efficiency analysis. Journal of Industrial Ecology 9(4): 25-41.

Idescat. Statistical Institute of Catalonia. 2016. Municipal database. http://www.idescat.cat/territ/BasicTerr?TC=9.

ISO 14040:2006. Environmental management - Life cycle assessment - Principles and framework. Geneva, Switzerland: International Organization for Standardization.

ISO 14045:2012. Environmental management — Ecoefficiency assessment of product systems — Principles, requirements and guidelines. Geneva, Switzerland: International Organization for Standardization.

ISO 15686-5:2008. Buildings and constructed assets - Sevice-life planning - Part 5: Life-cycle costing. Geneva, Switzerland: International Organization for Standardization.

Kägi, T., F. Dinkel, R. Frischknecht, S. Humbert, J. Lindberg, S. De Mester, T. Ponsioen, S. Sala, and U.W. Schenker. 2016. Session “Midpoint, endpoint or single score for decision-making?”-SETAC Europe 25th Annual Meeting, May 5th, 2015. The International Journal of Life Cycle Assessment 21(1): 129-132. http://link.springer.com/10.1007/s11367-015-0998-0. Accessed August 18, 2016.

Leeuwen, C.J. van, J. Frijns, A. van Wezel, and F.H.M. van de Ven. 2012. Cities Blueprints: 24 Indicators to Assess the Sustainability of the Urban Water Cycle. Water Resources Management 26(8): 2177-2197. http://link.springer.com/10.1007/s11269-012-0009-1. Accessed July 30, 2014.

Lemos, D., A.C. Dias, X. Gabarrell, and L. Arroja. 2013. Environmental assessment of an urban water system. Journal of Cleaner Production 54: 157-165. 
http://linkinghub.elsevier.com/retrieve/pii/S0959652613002643. Accessed July 30, 2014.

Lorenzo-Toja, Y., I. Vázquez-Rowe, M.J. Amores, M. Termes-Rifé, D. Marín-Navarro, M.T. Moreira, and G. Feijoo. 2016. Benchmarking wastewater treatment plants under an eco-efficiency perspective. Science of The Total Environment 566: 468479.

Loubet, P., P. Roux, E. Loiseau, and V. Bellon-Maurel. 2014. Life cycle assessments of urban water systems: A comparative analysis of selected peer-reviewed literature. Water Research 67: 187-202. http://www.sciencedirect.com/science/article/pii/S004313541400623X. Accessed September 19, 2014.

Makropoulos, C.K., K. Natsis, S. Liu, K. Mittas, and D. Butler. 2008. Decision support for sustainable option selection in integrated urban water management. Environmental Modelling \& Software 23(12): 1448-1460.

Marques, R.C., N.F. da Cruz, and J. Pires. 2015. Measuring the sustainability of urban water services. Environmental Science \& Policy 54: 142-151.

MetaBase ITeC. 2010. Online ITeC database: prices, technical details, companies, certificates, product pictures and environmental data. http://www.itec.cat/metabase. Accessed February 2013.

Morera, S., C. Remy, J. Comas, and L. Corominas. 2016. Life cycle assessment of construction and renovation of sewer systems using a detailed inventory tool. The International Journal of Life Cycle Assessment 21(8): 1121-1133. http://link.springer.com/10.1007/s11367-016-1078-9. Accessed August 3, 2016. 
Muga, H.E. and J.R. Mihelcic. 2008. Sustainability of wastewater treatment technologies. Journal of Environmental Management 88(3): 437-447.

Murla, D., O. Gutierrez, M. Martinez, D. Suñer, P. Malgrat, and M. Poch. 2016. Coordinated management of combined sewer overflows by means of environmental decision support systems. Science of The Total Environment 550: 256-264.

Petit-Boix, A., N. Roigé, A. de la Fuente, P. Pujadas, X. Gabarrell, J. Rieradevall, and A. Josa. 2016. Integrated Structural Analysis and Life Cycle Assessment of Equivalent Trench-Pipe Systems for Sewerage. Water Resources Management 30(3): 1117-1130.

Petit-Boix, A., D. Sanjuan-Delmás, S. Chenel, D. Marín, C. Gasol, R. Farreny, G. Villalba, et al. 2015. Assessing the energetic and environmental impacts of the operation and maintenance of Spanish sewer networks from a life-cycle perspective. Water Resources Management 29(8): 2581-2597.

Petit-Boix, A., D. Sanjuan-Delmás, C. Gasol, G. Villalba, M. Suárez-Ojeda, X. Gabarrell, A. Josa, and J. Rieradevall. 2014. Environmental Assessment of Sewer Construction in Small to Medium Sized Cities Using Life Cycle Assessment. Water Resources Management 28(4): 979-997. http://link.springer.com/10.1007/s11269-014-0528-z. Accessed April 29, 2014.

PRé Consultants. 2014. SimaPro 8.0.4. PRé Consultants, Amersfoort.

REE. Red Eléctrica de España. 2012. The Spanish electric system (El sistema eléctrico español). Retrieved from http://www.ree.es/sites/default/files/downloadable/inf_sis_elec_ree_2011_v3.pdf. 
Risch, E., O. Gutierrez, P. Roux, C. Boutin, and L. Corominas. 2015. Life cycle assessment of urban wastewater systems: Quantifying the relative contribution of sewer systems. Water Research 77: 35-48.

Termes-Rifé, M., M. Molinos-Senante, F. Hernández-Sancho, and R. Sala-Garrido. 2013. Life cycle costing: a tool to manage the urban water cycle. Journal of Water Supply: Research and Technology—AQUA. IWA Publishing, September 7. file://C:/Users/1218319/Downloads/2. Termes-Rifé etal WSJ 2013.pdf. Accessed April 9, 2015.

Thomas, A., B.R.K. Mantha, and C.C. Menassa. 2016. A Framework to Evaluate the Life Cycle Costs and Environmental Impacts of Water Pipelines. In Pipelines 2016, 1152-1163. Reston, VA: American Society of Civil Engineers, July 11. http://ascelibrary.org/doi/10.1061/9780784479957.107. Accessed August 2, 2016.

U.S. Army Corps of Engineers. 1998. Engineering and Design. Conduits, culverts, and pipes. Engineer Manual 1110-2-2902. Washington, DC 20314-1000.

Udo de Haes, H.A., G. Finnveden, M. Goedkoop, E. Hertwich, P. Hofstetter, W. Klöpffer, W. Krewitt, and E. Lindeijer. 2002. Life Cycle Impact Assessment: Striving towards best practice. Proceedings.

UN. United Nations. Department of Economic and Social Affairs. Population Division. 2012. World Urbanization Prospects: The 2011 Revision, CD-ROM Edition.

UNE 53331:1997. Plastics. Unplastized poly(vinyl chloride) and high and medium density polyethylene (PE) pipes. Criterion for the assessment of pipes for plastics piping systems with car without pressure under external loads. AENOR, Madrid, Spain. 
Vahidi, E., E. Jin, M. Das, M. Singh, and F. Zhao. 2015. Comparative Life Cycle Analysis of Materials in Wastewater Piping Systems. Procedia Engineering 118: 1177-1188. http://www.sciencedirect.com/science/article/pii/S1877705815021165. Accessed September 23, 2015.

Vahidi, E., E. Jin, M. Das, M. Singh, and F. Zhao. 2016. Environmental life cycle analysis of pipe materials for sewer systems. Sustainable Cities and Society.

Venkatesh, G. and H. Brattebø. 2011. Energy consumption, costs and environmental impacts for urban water cycle services: Case study of Oslo (Norway). Energy 36(2): 792-800. http://linkinghub.elsevier.com/retrieve/pii/S0360544210007309. Accessed January 29, 2013.

Venkatesh, G. and H. Brattebø. 2013. Typifying cities to streamline the selection of relevant environmental sustainability indicators for urban water supply and sewage handling systems: a recommendation. Environment, Development and Sustainability 15(3): 765-782. http://link.springer.com/10.1007/s10668-012-94051. Accessed August 2, 2016.

Venkatesh, G., J. Hammervold, and H. Brattebø. 2009. Combined MFA-LCA for Analysis of Wastewater Pipeline Networks. Journal of Industrial Ecology 13(4): 532-550. http://doi.wiley.com/10.1111/j.1530-9290.2009.00143.x. Accessed February 1, 2013.

\section{About the authors}

Anna Petit-Boix is currently a $\mathrm{PhD}$ student at the Sostenipra research group from the Institute of Environmental Science and Technology (ICTA), in the Autonomous University of Barcelona (UAB) in Bellaterra (Catalonia, Spain). 
Carla Arnal is an economist researcher at Cetaqua, Water Technology Center in Cornellà de Llobregat (Catalonia, Spain)

Desirée Marín is Head of the Environment, Society \& Economics research program at Cetaqua, Water Technology Center in Cornellà de Llobregat (Catalonia, Spain)

Alejandro Josa is a senior researcher and professor at the Department of Civil and Environmental Engineering, the School of Civil Engineering and the Institute of Sustainability (IS.UPC) of the Technical University of Catalonia (UPC) in Barcelona (Catalonia, Spain)

Xavier Gabarrell is a senior researcher and professor at the Department of Chemical, Biological and Environmental Engineering (UAB) and the Sostenipra research group in Bellaterra (Catalonia, Spain).

Joan Rieradevall is a senior researcher and professor at the Department of Chemical, Biological and Environmental Engineering (UAB) the Sostenipra research group in Bellaterra (Catalonia, Spain). 